\title{
BMJ Global Health COVID-19 caused significant declines in regular vitamin A supplementation for young children in 2020: what is next?
}

\author{
Andreas Hasman (D) , ${ }^{1}$ Annette Imohe (D) , ${ }^{1}$ Julia Krasevec, ${ }^{2}$ Grainne Moloney, \\ Victor M Aguayo ${ }^{1}$
}

\begin{abstract}
To cite: Hasman A, Imohe A Krasevec J, et al. COVID-19 caused significant declines in regular vitamin $\mathrm{A}$ supplementation for young children in 2020: what is next?BMJ Global Health 2021;6:e07507. doi:10.1136/ bmjgh-2021-007507
\end{abstract}

Handling editor Seye Abimbola

Received 22 September 2021 Accepted 24 October 2021

Check for updates

(c) Author(s) (or their employer(s)) 2021. Re-use permitted under CC BY-NC. No commercial re-use. See rights and permissions. Published by BMJ.

${ }^{1}$ Nutrition Section, Programme Group, UNICEF, New York, New York, USA

${ }^{2}$ Division of Data, Analytics, Planning and Monitoring, UNICEF, New York, New York, USA

Correspondence to Dr Andreas Hasman; ahasman@unicef.org
In efforts to restrict the spread of SARS-CoV-2, many low-income and middle-income countries suspended community-based public health and nutrition programmes in early 2020. At the time, the expectation was that disruptions due to the COVID-19 response would cause significant declines in programme coverage of key services, and eventually increase preventable morbidity and mortality among the most vulnerable children. ${ }^{1}$ The magnitude of the pandemic's impact on preventive vitamin A supplementation (VAS) programmes is now made visible in UNICEF's annual programme coverage data.

Regular administration of high-dose VAS to children 6-59 months old every 4-6 months reduces the risk of child mortality by $12 \%-24 \%$ in communities where vitamin A deficiency is prevalent. ${ }^{2}$ Prior to the pandemic, the global VAS programme reached over 200 million children annually with the recommended two VAS doses in countries with high child mortality. Between 2016 and 2019, coverage had been hovering at around $65 \%$ of eligible children. In the year prior to the COVID-19 outbreak, about 200 million eligible children benefited from the two annual doses of VAS, while 134 million missed out on at least one of the doses and therefore the full benefits of supplementation.

The situation deteriorated sharply following the March COVID-19 outbreak, primarily due to service delivery disruptions caused by pandemic containment measures. Based on administrative data analysed by UNICEF, ${ }^{3}$ there was a 19 percentage point decline in two-dose VAS coverage from 2019 (from $60 \%$ to $41 \%$; figure 1), with 62 million fewer children (ie, onethird) receiving both VAS doses in 2020. The steepest drops in coverage occurred in the first half of the year (figure 2) following recommendations to suspend mass public health and nutrition campaigns. ${ }^{4}$ Global VAS coverage thus fell from $72 \%$ in the first half of 2019 to $49 \%$ in the first half of 2020, while the number of children
Summary box

Service disruptions caused significant declines in coverage of vitamin A supplementation in 2020

- The largest declines were in the first half of the year, following widespread suspension of mass campaigns.

- Countries with the highest child mortality, and therefore the greatest need for supplementation, had the lowest coverage in 2020, reversing the situation in 2019

- In the context of COVID-19, vitamin A supplementation delivery through routine systems was more resilient than delivery in campaigns.

- To regain lost coverage and move towards universal coverage, countries must strengthen delivery systems with a renewed impetus to reach children most at risk.

covered fell from 239 million in the first half of 2019 to 165 million in the first half of 2020 (ie, a drop of almost a quarter). In the second half of 2020, when suspensions were rescinded, $57 \%$ or 192 million eligible children were reached compared with $63 \%$ or 211 million children in the second half of 2019 (a drop of only six percentage points).

Eight countries drove the sharp decline in two-dose coverage in 2020: Afghanistan, Cameroon, Chad, Niger, Nigeria, Pakistan, Sudan and Tanzania. In these countries, 85 million children were missed (ie, $43 \%$ of the total number of missed children). If the eight countries were to regain the coverage achieved in 2019, global VAS coverage would be $61 \%$. Arguably, they should be given priority attention to shore up the coverage of the global VAS programme.

It is also clear that countries with the greatest need for supplementation, that is, highest child mortality, had the lowest coverage in 2020. Out of the 48 countries from which we have data, 23 have under-5 


\section{Two-dose vitamin A coverage \\ $100 \%$

 \\ ○ 2020}

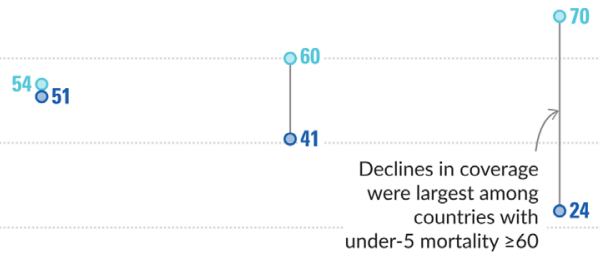

\begin{tabular}{|c|c|c|}
\hline $\begin{array}{l}\text { Countries with } \\
\text { U5MR }<60\end{array}$ & Global & $\begin{array}{c}\text { Countries with } \\
\text { U5MR } \geq 60\end{array}$ \\
\hline
\end{tabular}

Figure 1 Global vitamin A coverage decreased dramatically during 2020. Global vitamin A coverage declined by 19 percentage points between 2019 and 2020, with a 46 percentage point drop in coverage among countries with under- 5 mortality rates (U5MR) of 60 or more deaths per 1000 live births. Global estimates are based on administrative data for 48 countries: in 2019, 21 countries with U5MR <60, 27 countries with U5MR $\geq 60$; in 2020, 25 countries with U5MR <60, 23 countries with U5MR $>60$. Source: UNICEF, Estimates of vitamin A supplementation coverage in preschool-age children, Methods and processes for the UNICEF global vitamin A supplementation database. ${ }^{6}$

mortality rates (U5MR) of 60 or more deaths per 1000 live births. In these countries, only $24 \%$ of eligible children were reached with two doses of VAS in 2020. In contrast, VAS coverage in countries with U5MR of less than 60 per 1000 live births reached $51 \%$ (figure 1). This indicates that children in the most vulnerable contexts likely bore the brunt of pandemic-related disruptions.
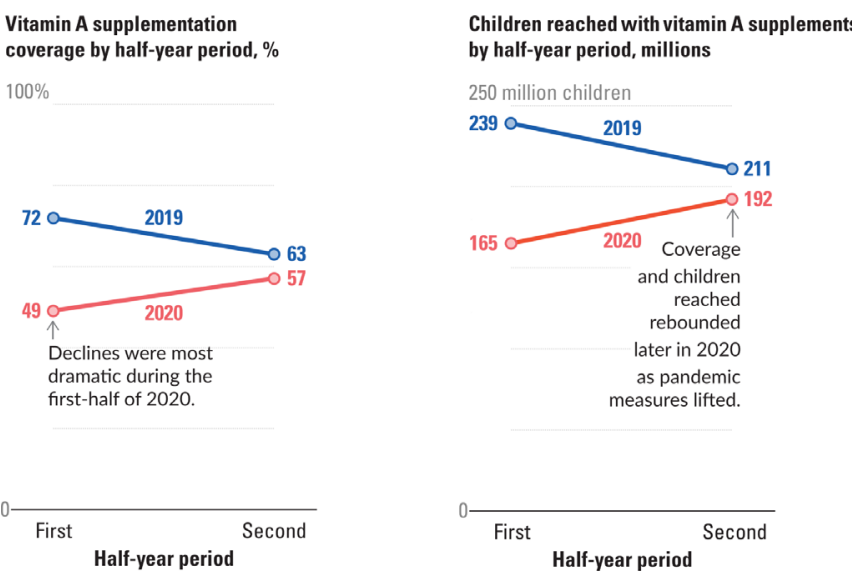

Figure 2 Declines in vitamin A coverage were largest during the first half of 2020. The suspension of public health and nutrition campaigns early in 2020 coincided with the most dramatic vitamin A coverage declines, with 74 million fewer children receiving their requisite vitamin $\mathrm{A}$ dose during the first half of 2020 compared with 2019. Global estimates are based on administrative data for 48 countries. Source: UNICEF, Estimates of vitamin A supplementation coverage in preschool-age children, Methods and processes for the UNICEF global vitamin A supplementation database. ${ }^{6}$
Although most countries experienced a decline in two-dose coverage, there were nuances: a few countries (Kenya, Madagascar, Mali and Papua New Guinea) were able to increase coverage by more than 10 percentage points. Further analysis is required to determine how these countries managed to reverse the general trend. However, initial observations indicate that countries delivering VAS through routine contacts fared better than countries relying on delivery through campaigns. Three of the four countries that achieved a significant increase in coverage used routine as their main delivery mechanism. In contrast, the 10 countries that experienced the largest drops in two-dose coverage relied predominantly on campaigns. This finding correlates with the fact that mass campaigns faced the most severe suspension and other kinds of disruptions in early 2020, while delivery through routine contacts continued in most places.

So what is next for countries as the pandemic runs its course and COVID-19 prospectively turns endemic? Our global VAS coverage data suggest that to regain lost coverage, minimise risks in vulnerable populations, build VAS delivery mechanisms that can withstand future shocks, and ultimately move towards universal VAS coverage, countries must strengthen service delivery systems with a renewed impetus to reach children most at risk - children living in high mortality settings-particularly in countries with large child populations. The UNICEF analysis suggests that, in 2020, delivery through routine systems was more resilient than delivery through campaigns, with some countries even managing to extend reach in the aftermath of the outbreak by further strengthening routine delivery. As coverage recovers, countries must also ensure that VAS addresses the unmet need among the most vulnerable children by prioritising children under 2 years as most under-5 mortality is concentrated in this age group. ${ }^{5}$

These lessons for VAS are of relevance to a range of public health and nutrition programmes, including immunisation, growth monitoring and promotion, and the early detection and treatment of severe wasting. Rebuilding coverage may present opportunities to improve sustainable health and nutrition outcomes beyond what was achieved prior to the pandemic.

Contributors $\mathrm{AH}$ and $\mathrm{Al}$ did data management, analysis and reporting and led the writing of the manuscript. JK contributed to the writing of the manuscript and provided critical review of the data analysis and reporting of results. VMA and GM provided supervision and critical revision of the analysis and the manuscript.

Funding The analysis in this paper was funded by UNICEF, Nutrition Section, Programme Group. UNICEF provides technical assistance to vitamin A supplementation programmes throughout the world and is receiving funding from the Government of Canada.

Competing interests None declared.

Patient consent for publication Not required.

Provenance and peer review Not commissioned; internally peer reviewed.

Data availability statement Data are available upon request.

Open access This is an open access article distributed in accordance with the Creative Commons Attribution Non Commercial (CC BY-NC 4.0) license, which 
permits others to distribute, remix, adapt, build upon this work non-commercially, and license their derivative works on different terms, provided the original work is properly cited, appropriate credit is given, any changes made indicated, and the use is non-commercial. See: http://creativecommons.org/licenses/by-nc/4.0/.

ORCID iDs

Andreas Hasman http://orcid.org/0000-0002-0431-2947

Annette Imohe http://orcid.org/0000-0003-3925-8423

\section{REFERENCES}

1 Roberton T, Carter ED, Chou VB, et al. Early estimates of the indirect effects of the COVID-19 pandemic on maternal and child mortality in low-income and middle-income countries: a modelling study. Lancet Glob Health 2020;8:e901-8.

2 Imdad A, Mayo-Wilson E, Herzer K, et al. Vitamin A supplementation for preventing morbidity and mortality in children from six months to five years of age. Cochrane Database Syst Rev 2017;3:CD008524.

3 UNICEF. Global vitamin A supplementation database. Available: data. unicef.org/topic/nutrition/vitamin-a-deficiency/ [Accessed Sep 2021].

4 Universal vitamin A supplementation for preschool-aged children in the context of covid-19: GAVA consensus statement, June 2020. Available: www.gava.org/content/user files/2020/04/GAVAConsensus-Statement-VAS-in-the-context-of-COVID-19-v.20200407. pdf [Accessed Sep 2021].

5 Hasman A, Moloney G, Aguayo V. Regular vitamin A supplementation: prioritizing the youngest children. Am J Clin Nutr 2021;114:390-1.

6 Unicef global vitamin A supplementation database. Available: https:// data.unicef.org/topic/nutrition/vitamin-a-deficiency/ 